ISSN 0103-9954

\title{
DINÂMICA NUTRICIONAL EM FLORESTA ESTACIONAL DECIDUAL COM ÊNFASE AOS MINERAIS PROVENIENTES DA DEPOSIÇÃO DA SERAPILHEIRA
}

\section{NUTRIENT CYCLING IN A SEASONAL DECIDUOUS FOREST WITH SPECIAL RESPECT TO THE MINERAL CONCENT PRODUCED BY THE LITTER FALL}

Girlei Costa da Cunha ${ }^{1}$ Luis Almiro Grendene ${ }^{2}$ Miguel Antão Durlo ${ }^{3}$ Delmar A. Bressan ${ }^{3}$

\section{RESUMO}

A produção anual de serapilheira, o conteúdo de $\mathrm{N}, \mathrm{P}, \mathrm{K}, \mathrm{Ca}$ e $\mathrm{Mg}$, a taxa de decomposição da serapilheira e a eficiência de utilização de nutrientes, foram estudadas em uma floresta, estacional decidual, situada nas encostas da Serra Geral em Santa Maria, Rio Grande do Sul. A produção anual de serapilheira foi de $7,76 \mathrm{t} / \mathrm{ha}$, com a fração folhas representando aproximadamente $66 \%$ da produção total. A estação de maior deposição de serapilheira e nutrientes foi a primavera. Foram depositados anualmente no solo florestal $206 \mathrm{Kg} / \mathrm{ha}$ de nitrogênio, $11,2 \mathrm{Kg} / \mathrm{ha}$ de fósforo, 37,8 $\mathrm{Kg} /$ ha de potássio, 269,2 Kg/ha de cálcio e $29,9 \mathrm{Kg}$ /ha de magnésio. A quantidade média de manta acumulada sobre o solo totalizou 6,7 $\mathrm{t} /$ ha, a estimativa da taxa instantânea de decomposição (k) foi de 1,16 e o tempo necessário para decomposição de $50 \%$ da serapilheira produzida foi estimado em torno de 7 meses. A eficiência da utilização de nutrientes

1 Engenheira Florestal, Graduada pelo Centro de Ciências Rurais, Universidade Federal de Santa Maria, Av. Roraima, 1000, CEP 97105-900, Santa Maria (RS), Brasil.

2 Engenheiro Florestal, Acadêmico do Curso de Ciências Biológicas, Centro de Ciências Naturais e Exatas, Universidade Federal de Santa Maria, Av. Roraima, 1000, CEP 97105-900, Santa Maria (RS), Brasil.

3 Engenheiro Florestal, Dr., Professor do Departamento de Ciências Florestais, Centro de Ciências Rurais, Av. Roraima, 1000, CEP 97105-900, Santa Maria (RS), Brasil. 
dada pela relação biomassa/nutriente para os elementos $\mathrm{N}, \mathrm{P}, \mathrm{Ca}$ e $\mathrm{Mg}$, foi menor do que tem sido verificada em outras florestas do Brasil, indicando que a produtividade primária da floresta não é limitada pela disponibilidade dos elementos estudados.

Palavras-chave: floresta estacional decidual; ciclagem de nutrientes; serapilheira; decomposição; eficiência de utilização de nutrientes.

\section{ABSTRACT}

Annual litter fall, the $\mathrm{N}, \mathrm{P}, \mathrm{K}, \mathrm{Ca}$ and $\mathrm{Mg}$ content, litter decomposition rate and the nutrient use efficiency were studied in a deciduous seasonal forest, from 'Serra Geral' escarpments, in Santa Maria, Rio Grande do Sul state. The annual litter fall reached $7.76 \mathrm{t} / \mathrm{ha}$, with leaf fraction representing $66 \%$ of the total. Spring was the most intensive litter fall and nutrient deposition season. This of nitrogen, $11,2 \mathrm{Kg} / \mathrm{ha}$ of phosphorus, 37,8 $\mathrm{Kg} / \mathrm{ha}$ of potassium, $269.2 \mathrm{Kg} / \mathrm{ha}$ of calcium and $29.9 \mathrm{Kg} / \mathrm{ha}$ of magnesium. The mean forest floor mass was $6.7 \mathrm{t} / \mathrm{ha}$, the instantaneous decomposition rate $(\mathrm{K})$ was estimated to be 1.16 and the time necessary to decay $50 \%$ of the total litter was around 7 months. The nutrient use efficiency, given by the biomass/nutrient rate to the $\mathrm{N}, \mathrm{P}, \mathrm{Ca}$ and $\mathrm{Mg}$ elements was lesser than those verified for other Brazilians regions, showing that the primary productivity of the stand in not limited by the availability of the studied nutrients.

Keywords: deciduous seasonal forest; nutrient cycling; litter; decomposition; nutrient use efficiency.

\section{INTRODUÇÃO}

A serapilheira é a principal via de transferência de nutrientes das plantas ao solo, em ecossistemas florestais. Assim, o estudo da ciclagem de nutrientes minerais, via serapilheira, é fundamental para conhecer a estrutura e funcionamento de tais ecossistemas.

A formação florestal que ocorre ne região de estudo é classificada, segundo Klein (1983), como Floresta Estacional Decidual. Primitivamente, a área florestal estendia-se desde o Rio Ibicuí, a oeste do Rio Grande do Sul, até o Vale do Rio Cai, a leste, ocupando os contrafortes 
da Serra Geral.

A partir do processo de colonização da Região da Fralda da Serra Geral, a área foi severamente reduzida e as matas que não foram derrubadas, em sua maioria, sofreram a exploração seletiva das árvores mais valiosas.

Atualmente, as florestas remanescentes compõem um mosaico formado por vários estágios de desenvolvimento ou de degradação. $\mathrm{O}$ potencial produtivo dos solos e das florestas naturais não é devidamente utilizado por falta de conhecimentos básicos a respeito da ecologia da formação florestal.

Em razão destas premissas, o presente estudo teve como objetivos:

a) Avaliar o comportamento e a produção anual de serapilheira, segregada em quatro frações distintas;

b) Determinar as concentrações de N, P, K, Ca e $\mathrm{Mg}$ na serapilheira ao longo do ano e calcular a transferência anual destes nutrientes ao solo, por esta via;

c) Estimar a velocidade de decomposição de serapilheira;

d) Calcular a eficiência de utilização de N, P, Ca e Mg pela vegetação da floresta estudada, comparando com outras florestas tropicais e subtropicais.

\section{REVISÃO DE LITERATURA}

O estudo de ciclagem de nutrientes minerais nos ecossistemas, ao lado daqueles referentes ao fluxo de energia, é fundamental para o conhecimento da estrutura e do funcionamento de tais ecossistemas. Fornecendo, dessa maneira, informações básicas para planejar alternativas para seu desenvolvimento (HERRERA et al., 1981). Além disso, a ciclagem de nutrientes informa sobre a resistência do ecossistema a diversos fatores de tensão decorrentes, principalmente, da atividade humana (MEGURO et al., 1979). 
As relações quantitativas de ciclagem de nutrientes minerais nos ecossistemas, como parte integrante do ciclo bioquímico geral, são, na atualidade, objetos de numerosos estudos em todas as regiões do globo. Na América tropical e subtropical, as pesquisas a respeito são, na maioria, bastante recentes e abordam aspectos parciais de comportamento nutricional de ecossistemas florestais.

No Brasil destacam-se os trabalhos de Klinge \& Rodrigues (1968 a.b.), Luisão \& Schubart (1987) estudando a ciclagem de nutrientes via serapilheira, na Amazônia em Floresta de Terra Firme; os de Stark (1971) e Andrae \& Krapfenbauer (1983) que realizaram inventários de nutrientes em Floresta Tropical úmida e povoamento de Araucaria angustifolia no Rio Grande do Sul, respectivamente; e Meguro et al. (1979), Carpanezzi (1980) e Poggiani \& Monteiro Jr. (1990) que estudaram a deposição de serapilheira e nutrientes em florestas semidecíduas em São Paulo.

O outro ciclo reconhecido por Pritchett (1986), denominase ciclo biológico ou interno, que pode ser subdividido em ciclo bioquímico (dentro da planta), e ciclo biogeoquímico entre o solo e a planta. Esse ciclo também é chamado de ciclo fechado e envolve algumas etapas, a saber: absorção, translocação, retenção e restituição de nutrientes, por parte da vegetação que constitui o ecossistema.

Pritchett (1986) admite dois ciclos de nutrientes no ecossistema florestal. O ciclo geoquímico ou aberto, que envolve a transferência de elementos dentro e/ou fora do ecossistema. As entradas no ecossistema são devidas aos nutrientes do ar, às precipitações, à intemperização das rochas, à fixação biológica do nitrogênio e também à fertilização artificial. As saídas, por outro lado, são representadas pelas perdas, por erosão, lavagens, volatização e pela remoção de nutrientes pela exploração florestal. 
A vegetação devolve nutrientes ao solo através da circulação de matéria, que é representada pela deposição de serapilheira, galhos grossos e troncos, e pela morte de raízes, principalmente as finas (VOGT et al., 1986). Outro modo de transferência de nutrientes da vegetação para o solo é pelas águas de precipitação interna da floresta e escorrimento pelos troncos (ARCOVA \& CICCO, 1987).

A serapilheira é a principal via de transferência de carbono, nitrogênio, fósforo e cálcio; o potássio é devolvido principalmente através da precipitação interna e o magnésio é variável entre diferentes florestas (COLE \& RAPP, 1980).

Três métodos têm sido utilizados para estudar a decomposição da serapilheira no campo. O primeiro é aplicado em floresta decíduas típicas, cujo período de queda da serapilheira total é restrito; a decomposição pode então ser facilmente estudada em intervalos regulares após a queda da serapilheira (REMEZOV, 1961). O segundo método utiliza o enclausuramento de quantidades definidas de serapilheira, normalmente em saquinho de tela de náilon, que são deixados no campo por determinado período de tempo (ATTIWILL, 1968). O terceiro método é aplicado quando o peso das camadas da manta e a queda anual de serapilheira são conhecidas e uma "constante anual de decomposição" pode ser calculada (OLSON, 1963).

Consoante com Cuevas \& Medina (1986), a quantidade e qualidade de nutrientes fornecidos ao solo, pela deposição da serapilheira, é variável, sendo dependente, principalmente, das espécies que compõem a formação florestal e da disponibilidade de nutrientes no solo. Segundo estes autores, a vegetação que ocorre naturalmente em um local é adaptada aos suprimentos nutricionais existentes no solo, apresentando, dessa maneira, uma eficiência de uso, para cada nutriente, grande ou não. 
Conforme Vitousek (1982), a eficiência com que uma floresta utiliza nutrientes, é definida como a quantidade de matéria orgânica perdida das plantas ou permanentemente estocada dentro das mesmas, por unidade de nutriente perdido ou permanentemente estocado. Logo, a eficiência pode ser calculada para a biomassa viva ou morta. A serapilheira pode ser a principal via de transferência de matéria orgânica, nitrogênio, fósforo e cálcio é utilizada, para comparar a eficiência de utilização de nutrientes, em diferentes florestas. A fração folhas de serapilheira, por apresentar pequena variação em sua distribuição espacial, em seu conteúdo de nutrientes, e por ser a responsável pela maior parte da transferência anual de nutrientes ao solo, se torna a fração mais adequada para comparação entre ecossistemas florestais, no tocante à eficiência de seus componentes vegetais na utilização de nutrientes. Os nutrientes menos disponíveis apresentaram uma alta eficiência de uso pela vegetação, e vice-versa.

\section{MATERIAL E MÉTODOS}

O local escolhido para estudar a ciclagem de nutrientes em Floresta estacional decidual, foi o "Morro do Elefante", distante $4 \mathrm{~km}$ ao norte da Universidade Federal de Santa Maria - RS. As coordenadas geográficas aproximadamente são $53^{\circ} 45^{\prime} \mathrm{W}$ e $29^{\circ} 40^{\prime}$ S. O referido morro situa-se entre as cotas altimétricas de $100 \mathrm{~m}$ e $469 \mathrm{~m}$, entretanto, o presente trabalho foi instalado entre as cotas $300 \mathrm{~m}$ e $469 \mathrm{~m}$, com inclinação média de $30^{\circ}$, exposta ao sul, onde a floresta está mais conservada. 
Dinâmica nutricional em floresta estacional decidual com ênfase ... 41

\section{Caracterização do solo e clima}

A formação da Serra Geral, na Região de Santa Maria, está representada por uma sucessão de 4 derrames de lava, de natureza basáltica, associadas a arenitos intercalados (SARTORI et al., 1975).

Pelo levantamento de solos do Rio Grande do Sul (LEMOS, 1973), os solos da área de estudo classificam-se como Litólicos Eutróficos. Derivados de rochas eruptivas básicas. São solos pouco desenvolvidos e o afloramento de rochas é bastante comum, em virtude do relevo fortemente ondulado. São ligeiramente ácidos e neutros, com elevados teores de cálcio, magnésio e potássio, alta saturação de bases e sem problemas de alumínio trocável. O teor de matéria orgânica é alto. No entanto, o teor de fósforo disponível é baixo, sendo em geral menor que $5 \mathrm{ppm}$. Em análise feita com o solo do local de estudo, chegaram-se aos resultados da Tabela 1.

TABELA 1: Características do solo da manta em que foi instalado o experimento. TABLE 1: Characteristics of soil of the plaid where the experiment was set.

\begin{tabular}{c|c|c|c|c|c|c|c}
\hline $\begin{array}{c}\text { Profundidade } \\
(\mathrm{cm})\end{array}$ & $\begin{array}{c}\text { Argila } \\
(\%)\end{array}$ & $\begin{array}{c}\mathrm{PH} \\
\mathrm{H} 2 \mathrm{O}\end{array}$ & $\begin{array}{c}\mathrm{MO} \\
(\%)\end{array}$ & $\begin{array}{c}\mathrm{P} \\
(\mathrm{ppm})\end{array}$ & $\begin{array}{c}\mathrm{K} \\
---\end{array}$ & $\begin{array}{c}\mathrm{Ca}+\mathrm{Mg} \\
\mathrm{meq} / 100 \\
\mathrm{~cm}^{3}\end{array}$ & $\begin{array}{c}\mathrm{Al} \\
--\end{array}$ \\
\hline $0-10$ & 13,0 & 6,0 & 7,5 & 9,3 & 0,5 & 15,2 & 0,0 \\
\hline
\end{tabular}

Conforme a classificação climática de Köppen, a região apresente clima subtropical do tipo Cfa. A temperatura média anual é de $19,2^{\circ} \mathrm{C}$ (variando as temperaturas mensais entre $14^{\circ} \mathrm{e}$ 
$25^{\circ} \mathrm{C}$ ). A precipitação total anual atinge $1.691 \mathrm{~mm}$, com chuvas mais ou menos uniformemente distribuídas ao longo do ano (MOTA et al., 1971).

Os dados referentes às precipitações e temperaturas médias mensais, no período de estudo, foram tomados juntos à estação Climatológica do Departamento de Fitotecnia da UFSM, situada aproximadamente $5 \mathrm{~km}$ ao sul da área de estudo.

\section{Caracterização da floresta}

A mata em estudo pertence à floresta Estacional Decidual, denominação esta, devido à abundância de indivíduos de espécies decídua, no estrado emergente, ser superior a 50\% (KLEIN, 1983). A espécie mais característica originalmente era a grápia.

Machado \& Longhi (1993) realizaram um levantamento florístico e fitossociológico na floresta do "Morro do Elefante". Eles relataram que a floresta é bastante densa, apresentando 925 árvores por hectare com CAP (circunferência a altura do peito) maior ou igual a $30 \mathrm{~cm}$. Foram identificadas 67 espécies arbóreas, dentre as quais, as de maior valor IVI (índice de valor de importância) são, em ordem: Nectandra magapotamica, Trichilia clausseni, Cupania vernalis, Enterolobium contortisiliquum, Alchornea triplinervia, Prunus subcoriacae, Allophylus edulis, Casearia silvestris, Ficus luschnathiana, Eugenia rostrifolia e Cabralea canjerana.

\section{Produção de serapilheira}

Para avaliar a quantidade de serapilheira produzida anualmente, foram instalados 25 coletores confeccionados em madeira, com $0,25 \mathrm{~m}^{2}$ de área de captação $(0,50 \times 0,50 \mathrm{~m})$, profundidade de $10 \mathrm{~cm}$ e fundo de tela de náilon fina, sustentados $10 \mathrm{~cm}$ acima do solo, para evitar contaminações. 
Os coletores foram distribuídos de modo a cobrir uma faixa de $10 \mathrm{~m}$ de largura acompanhando o gradiente de altitude do morro, entre as cotas de 300 e $470 \mathrm{~m}$.

As coletas foram feitas mensalmente, entre junho de 1990 e maio de 1991 e a serapilheira segregada nas seguintes frações: a) folhas; b) galhos finos; c) flores, frutos e sementes; d) detritos (restos vegetais não identificados, casca de galhos e troncos, artrópodes, excremento de aves, etc.). Após a separação das frações da serapilheira de todos os coletores individualmente, estas foram secas em estufa a $85^{\circ} \mathrm{C}$ por $48 \mathrm{~h}$ e pesadas em balança analítica $(0,02$ g). Posteriormente, as frações semelhantes dos coletores, correspondentes a um mês de acumulação foram reunidas e trituradas em moinho tipo "Wiley" com peneira de $0,5 \mathrm{~mm}$. O material moído foi armazenado em frascos de vidro com tampas plásticas.

\section{Análises químicas e quantificação de nutrientes}

Alíquotas, de cada fração da serapilheira mensal, foram tomadas para análises químicas. As amostras sofrerão digestão com Ácido sulfúrico e sais catalizadores para a obtenção de extratos para a determinação de nitrogênio, ou digestão nítricoperclórica para obtenção de extratos para quantificação dos teores de $\mathrm{P}, \mathrm{K}, \mathrm{Ca}$ e $\mathrm{Mg}$. A determinação de $\mathrm{N}$ foi feita por destilação a vapor, pelo método de micro-Kjedahl. $\mathrm{O}$ fósforo foi determinado colorimetricamente em espectrofotômetro convencional, pelo método do vanadomolibdato de amônio. O potássio foi determinado em fotômetro de chama, enquanto o cálcio e o magnésio foram determinados em espectrofotômetro de absorção atômica. Os métodos de análise química estão descritos em Sarruge \& Haag (1974).

Para determinar as quantidades de nutrientes transferidos 
mensalmente pelas diferentes frações da serapilheira em $\mathrm{Kg} / \mathrm{ha}$, multiplicou-se o peso seco das frações, pelas respectivas concentrações dos elementos.

\section{Decomposição da serapilheira}

No presente estudo, optou-se por estimar a taxa de decomposição da serapilheira pelo método de Olson (1963).

Para quantificação da manta acumulada sobre o solo, mensalmente, na mesma oportunidade em que se recolhia a serapilheira dos coletores, retirava-se dez amostras aleatórias, com $0,25 \mathrm{~m}^{2}$, da manta acumulada sobre o solo. Para tanto, utilizava-se um gabarito de madeira quadrado e uma fração para demarcar a área a ser coletada.

No laboratório, antes de secar as amostras de manta a $85^{\circ} \mathrm{C}$ por $48 \mathrm{~h}$, separavam-se eventuais raízes finas e galhos maiores do que $1 \mathrm{~cm}$ em diâmetro, descartando-os.

A constante anual ou taxa instantânea de decomposição "K" proposta por Olson (1963), foi calculada pela relação entre a quantidade de serapilheira produzida anualmente (L) e a quantidade média de manta acumulada sobre o solo (Xss); assumindo-se que a manta já tenha atingido um estado de equilíbrio entre a produção e a decomposição da serapilheira $(\mathrm{K}=\mathrm{L} / \mathrm{Xss})$.

Os períodos de tempo, em anos, necessários para a decomposição de $50 \%$ e $95 \%$ de uma determinada porção de serapilheira, foram calculadas pelas respectivas equações, propostas por Olson (1963):

$$
\begin{aligned}
& \mathrm{t}_{0,5}=-\ln 0,5 \times \mathrm{K}^{-1} \\
& \mathrm{t}_{0,05}=3 \mathrm{x} \mathrm{K}^{-1}
\end{aligned}
$$

\section{Eficiência de utilização de nutrientes}

A eficiência de utilização de nutrientes pode ser calculada através da relação entre a biomassa de serapilheira produzida e a quantidade de nutrientes transferida por esta fração 
Dinâmica nutricional em floresta estacional decidual com ênfase ... 45

(VITOUSEK, 1982).

A eficiência de utilização de nutrientes, no presente estudo, foi vista como uma propriedade coletiva dos indivíduos que compõem a floresta. Assim, calculou-se a eficiência da utilização de N, P, Ca e Mg, na fração folhas da serapilheira, para possibilitar comparações com outras florestas. A metodologia empregada foi a de Vitousek (1982), através da relação biomassa/nutriente.

\section{RESULTADOS E DISCUSSÃO}

\section{Produção de serapilheira}

Os resultados demonstrados e discutidos neste trabalho, referem-se ao primeiro, dos três anos de estudo que estão sendo executados. A necessidade de maior tempo de amostragem, deve-se às possíveis variações anuais na produção de serapilheira, normalmente reportadas para florestas de folhosas.

A deposição anual de serapilheira, no primeiro ano de observação, alcançou 7,76 t/ha. Este valor é aproximadamente 30\% superior ao estimado por Vogt et al. (1986) para florestas de latifoliadas nesta latitude. Porém, enquadra-se dentro do intervalo encontrado em outras florestas brasileiras, conforme reportado por Klinge \& Rodrigues (1968a); Merugo et al. (1979); Carpanezzi (1980); Poggiani \& Monteiro Jr. (1990); Britez et al. (1992), por exemplo.

A Figura 1 demonstra o comportamento da queda de serapilheira de 10 de junho de 1990 a 10 de maio de 1991 e o curso das precipitações neste período. A Figura 2 exibe o comportamento das temperaturas médias mensais e a queda da serapilheira para o mesmo período.

Observando as Figuras 1 e 2 nota-se que as menores deposições de serapilheira foram verificadas no outono, ao passo que as maiores ocorreram entre agosto e novembro, na primavera, quando as precipitações foram abundantes e a temperatura média mensal estava em elevação. 


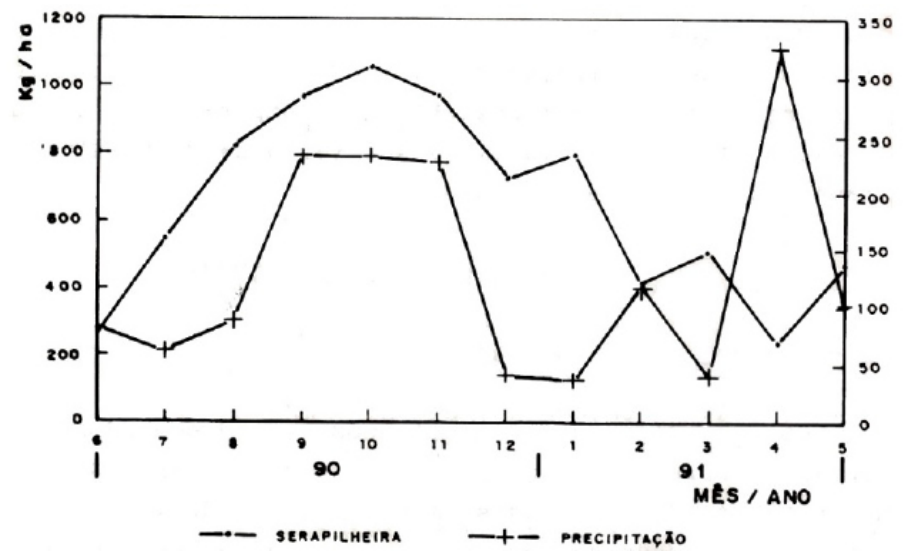

FIGURA 1: Comportamento da queda de serapilheira e das precipitações pluviométricas no período de estudo.

FIGURE 1: Behavior of litter fall and the rain falls in the studied period.

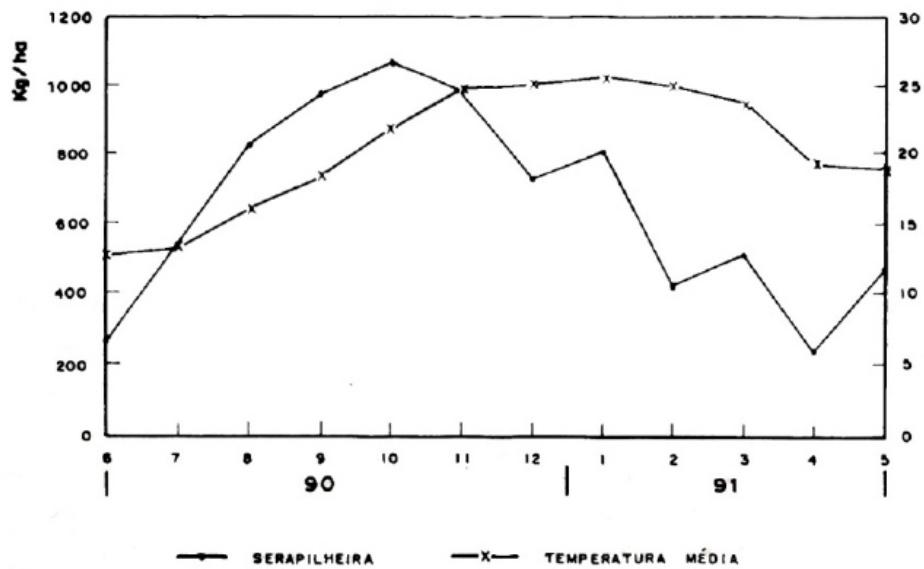

FIGURA 2: Comportamento da queda de serapilheira e da temperatura média mensal no período de estudo.

FIGURE 2: Behavior of the litter fall and of the monthly mean temperature in the studied period. 
O padrão sazonal de produção de serapilheira verificado é semelhante ao reportado por Britez et al. (1992), para uma floresta de araucária no Paraná. Estes autores, também, observaram uma maior queda de serapilheira na primavera, coincidindo com aumentos de precipitações e temperatura. Estas florestas situamse em zonas de clima subtropical, o qual não se caracteriza por períodos prolongados de frio intenso nem de seca. A ausência destes extremos climáticos, aliada à diversidade florística nestas regiões, permitem que a floresta produza serapilheira durante todo o ano, embora com uma acentuação da abscisão foliar após o inverno, antes que a maioria da vegetação retome o crescimento.

\section{Composição da serapilheira}

O total de serapilheira produzida foi analisada em quatro diferentes frações. As folhas constituirão a fração mais expressiva, representando aproximadamente $66 \%$ da produção total anual. A fração galhos representou $21,7 \%$, os detritos $9,9 \%$ e as flores, frutos e sementes $2,7 \%$ da serapilheira produzida anualmente. As frações galhos, detritos e flores, frutos e sementes apresentaram proporções muito variáveis dentro de diferentes formações florestais, não servindo para comparações de produção de massa. Por esta razão, a fração folhas, sozinha, é comumente empregada para a comparação da produção de serapilheira em diferentes ecossistemas florestais. Como se trata do primeiro ano de observação optou-se pela segregação das diferentes frações para detectar seu comportamento. Pelos resultados encontrados, fica evidenciado que, também para a floresta em estudo, a produção de serapilheira pode ser razoavelmente estimada, apenas pela queda da fração de folhas.

A Figura 3 demostra a deposição de serapilheira separada por fração, no período de estudo. Observa-se uma tendência 
sazonal na queda de folhas, galhos e detritos. As frações folhas e galhos finos foram as que determinaram as características da curva de deposição, por apresentarem, em todos os períodos de coleta, a maior percentagem (aproximadamente 87\%) do material recolhido.

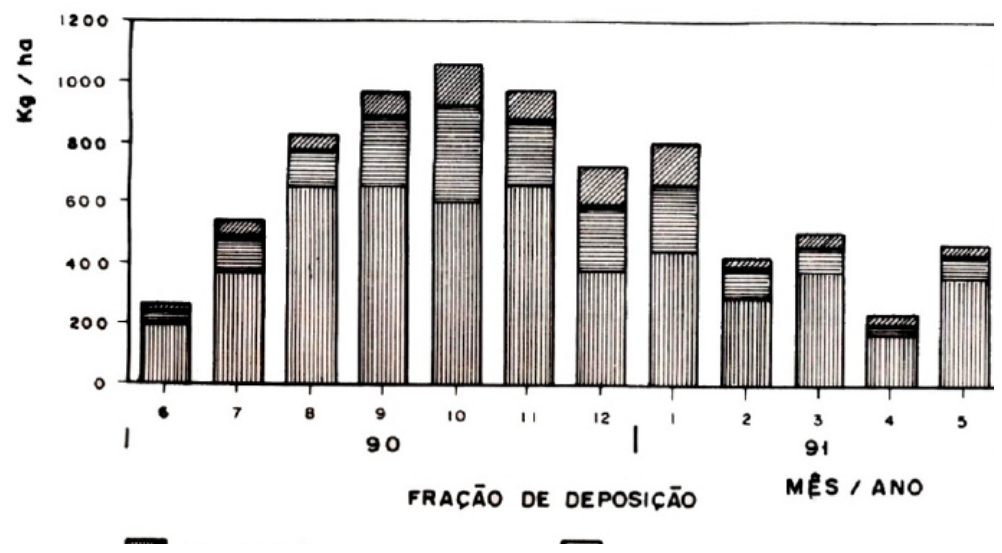

FIGURA 3: Deposição da serapilheira segregada em diferentes frações.

FIGURE 3: Deposition of the segregated litter in different fractions.

Apesar da pequena distância entre os coletores, durante o ano, observaram-se variabilidades espaciais bastante elevadas na queda de serapilheira (Tabela 2). A variação espacial foi mais marcada para a fração flores, frutos e sementes. A variação para galhos e detritos foi a metade da encontrada na queda de órgãos reprodutivos. A fração folhas e o total foram as que apresentaram menor variação entre os diferentes pontos de coleta.

A maior variação espacial encontrada para a queda de órgãos reprodutivos reflete a variabilidade da composição florística. As diferentes 
espécies vegetais componentes do ecossistema, possuem flores, frutos e sementes, com massa diferente e são, além disso, produzidas em distintas quantidades e épocas do ano (BRAY \& GORHAM, 1964).

TABELA 2: Queda média mensal de folhas; galhos; flores; frutos e sementes

(FFS); detritos (DET) e total de serapilheira produzida, com o respectivo, coeficiente de variação. "N" representa o número de coletores.

TABLE 2: Fall monthly average of leaves; branches; flowers; fruit and seeds (FFS); debris (DET) and total litter produced, with the corresponding, coefficient of variation. " $\mathrm{N}$ " represents the number of collectors

\begin{tabular}{|c|c|c|c|c|c|c|c|c|c|c|c|}
\hline \multirow[t]{2}{*}{ Mês } & \multirow[t]{2}{*}{$\mathrm{N}$} & \multicolumn{2}{|c|}{ Folhas } & \multicolumn{2}{|c|}{ Galhos } & \multicolumn{2}{|c|}{ FFS } & \multicolumn{2}{|c|}{ DE T } & \multicolumn{2}{|c|}{ Total } \\
\hline & & $\mathrm{X}$ & $\mathrm{CV}$ & $\mathrm{X}$ & $\mathrm{CV}$ & $\mathrm{X}$ & $\mathrm{CV}$ & $\mathrm{X}$ & $\mathrm{CV}$ & $\mathrm{X}$ & $\mathrm{CV}$ \\
\hline Jun & 24 & 193,5 & 35,8 & 48,5 & 97,1 & 5,2 & 207,7 & 12,5 & 108,0 & 259,7 & 39,1 \\
\hline Jul & 24 & 363,7 & 44,2 & 111,1 & 64,4 & 19,6 & 361,8 & 45,2 & 185,4 & 539,6 & 39,4 \\
\hline Ago & 25 & 642,5 & 37,9 & 125,6 & 74,4 & 14,1 & 178,7 & 41,1 & 104,9 & 823,3 & 33,3 \\
\hline Set & 25 & 650,0 & 37,8 & 224,6 & 68,2 & 13,9 & 129,5 & 79,1 & 55,2 & 967,6 & 33,9 \\
\hline Out & 25 & 601,0 & 25,5 & 307,4 & 85,1 & 22,3 & 168,6 & 125,7 & 97,5 & $1.056,4$ & 40,2 \\
\hline Nov & 25 & 653,3 & 35,3 & 198,1 & 55,6 & 28,3 & 94,7 & 91,0 & 62,3 & 970,7 & 33,0 \\
\hline Dez & 25 & 374,2 & 38,1 & 187,5 & 63,8 & 34,4 & 175,3 & 125,6 & 50,3 & 721,7 & 38,2 \\
\hline Jan & 25 & 438,2 & 27,6 & 209,3 & 60,1 & 14,7 & 144,2 & 138,1 & 39,1 & 800,3 & 25,8 \\
\hline Fev & 25 & 284,6 & 27,5 & 93,4 & 100,6 & 17,9 & 193,9 & 20,7 & 70,5 & 416,6 & 34,2 \\
\hline Mar & 25 & 372,6 & 33,4 & 79,0 & 82,8 & 13,5 & 138,5 & 41,2 & 67,7 & 506,3 & 32,9 \\
\hline Abr & 24 & 167,5 & 32,2 & 36,2 & 145,8 & 6,8 & 154,4 & 21,5 & 69,8 & 232,0 & 36,4 \\
\hline Mai & 25 & 354,5 & 40,2 & 65,6 & 82,9 & 20,0 & 255,0 & 27,9 & 130,5 & 468,0 & 42,5 \\
\hline & & & & & & & & & & & \\
\hline
\end{tabular}

*Os dados referentes às médias são expressos em Kg/ha. Coeficiente de variação em \%.

Admitindo-se um erro padrão da média, inferior a $10 \%$ como satisfatório, o número de coletores foi suficiente para dar estimativas adequadas da quantidade de serapilheira total e da fração de folhas (Figura 4). Para reduzir o erro padrão de mais frações a um erro inferior 
a $10 \%$ da média, seria necessário aumentar em várias vezes o número de coletores, o que se tornaria muito trabalhoso, sem dar uma correspondente contribuição às discussões e conclusões do trabalho.

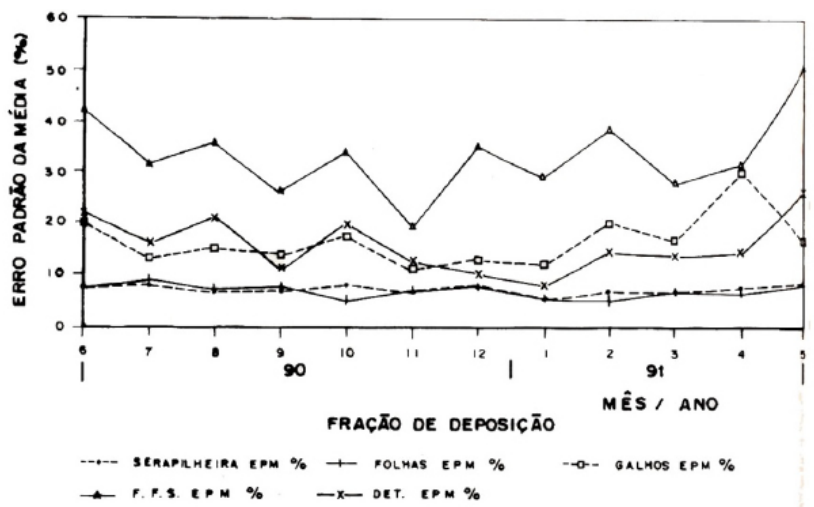

FIGURA 4: Erro padrão da média (\%) para as diferentes frações e para o total da serapilheira em cada mês de coleta.

FIGURE 4: Standard error of the average (\%) for the different fractions and the total litter in each month of collection.

\section{Conteúdo de macronutrientes na serapilheira}

A Tabela 3 demonstra as concentrações médias anuais de N, P, K, $\mathrm{Ca}$ e $\mathrm{Mg}$ nas diversas frações da serapilheira.

TABELA 3: Conteúdo médio de nutrientes $(\%) \pm$ desvio padrão das frações da serapilheira.

TABLE 3: Average nutrient content (\%) + standard deviation of litter fractions.

\begin{tabular}{lcccccc}
\hline & $\mathrm{N}$ & $\mathrm{P}$ & $\mathrm{K}$ & $\mathrm{Ca}$ & $\mathrm{Mg}$ \\
\hline Folhas & $2,90 \pm 0,21$ & $0,15 \pm 0,02$ & $0,58 \pm 0,21$ & $3,87 \pm 0,31$ & $0,43 \pm 0,04$ \\
Galhos & $1,82 \pm 0,27$ & $0,10 \pm 0,01$ & $0,35 \pm 0,08$ & $2,53 \pm 0,63$ & $0,25 \pm 0,02$ \\
F.F.S & $2,57 \pm 0,46$ & $0,21 \pm 0,04$ & $0,79 \pm 0,39$ & $1,44 \pm 0,37$ & $0,32 \pm 0,05$ \\
Detritos & $2,95 \pm 0,58$ & $0,21 \pm 0,03$ & $0,39 \pm 0,14$ & $2,85 \pm 0,27$ & $0,36 \pm 0,06$ \\
\hline
\end{tabular}


A fração de detritos apresenta altas concentrações de N, $\mathrm{P}$ e Ca, devido a sua composição, que inclui fragmentos vegetais não identificados, restos de insetos, cascas de árvores e galhos, excrementos de aves, etc. A fração flores, frutos e sementes é caracterizada pelos altos conteúdos de fósforo e potássio e pelas baixas concentrações de cálcio. Os galhos finos apresentam os menores conteúdos de $\mathrm{N}, \mathrm{P}, \mathrm{K}$ e Mg. As folhas detêm as maiores concentrações de cálcio e magnésio.

A Figura 5 demonstra o curso anual no conteúdo de nutrientes na fração de folhas e na serapilheira. Observa-se que para qualquer nutriente estudado, as concentrações na serapilheira refletem as da fração folhas. Isso se deve ao fato da serapilheira ser formada principalmente por folhas $(66 \%)$ e galhos finos $(21,7 \%)$ e as primeiras possuírem relativamente mais nutrientes que os últimos.

As concentrações de N, P, Ca e Mg nas folhas mostraram pouca variação ao longo do ano. Este fato foi um tanto inesperado, em virtude do grande número de espécies que compõem a floresta e da importância que cada uma tem na produção de serapilheira ao longo do ano. A importância relativa das diferentes espécies pôde ser percebida mesmo sem a análise separada por espécie. A estabilidade nas concentrações desses elementos e consequentemente nas relações entre eles, significa que a qualidade da serapilheira pouco se altera durante o ano. Isto sugere que, neste caso, a serapilheira influencia a dinâmica anual de populações de organismos do solo e o fornecimento de nutrientes, mais em função de sua quantidade do que de variação em sua qualidade.

O potássio demonstrou comportamento distinto dos demais nutrientes estudados, com suas concentrações variando bastante durante $o$ ano. As menores concentrações de potássio na serapilheira foram observadas no período de maior precipitação, assim como as mais elevadas foram verificadas nos meses 
em que as precipitações pluviométricas foram relativamente menores. Este comportamento é compreensível, pois este elemento encontra-se nos vegeteis principalmente na forma iônica, sendo, portanto, altamente suscetível ao processo de lavagem (ARCOVA \& CICCO, 1987).
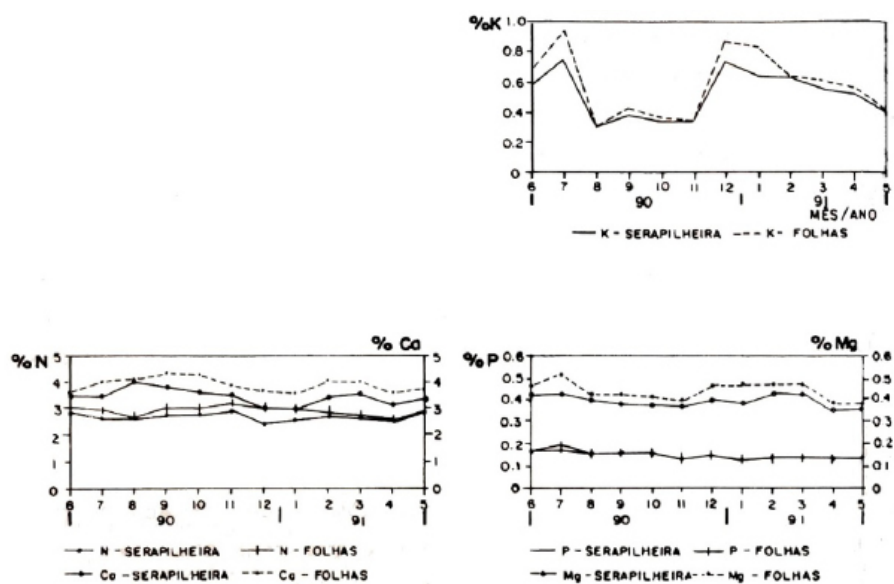

FIGURA 5: Curso anual no conteúdo de nutrientes na serapilheira e fração de folhas.

FIGURE 5: Annual course on the content of nutrients in litter and leaf fractions.

\section{Fornecimento de nutrientes}

A maior contribuição para ciclagem de nutrientes é oferecida pela fração folhas. A Tabela 4 demonstra as quantidades anuais de nutrientes depositados através das diferentes frações da serapilheira. A participação das folhas nos totais de nutrientes transferidos oscilou de 67,5 a $75 \%$. Os galhos finos, mesmo representando quase $22 \%$ da massa da serapilheira, não alcançaram tal importância no fornecimento de nutrientes, transferindo ao redor de $15 \%$ da quantidade dos diferentes elementos estudados.

A fração detritos tem uma contribuição variável na ciclagem, 
Dinâmica nutricional em floresta estacional decidual com ênfase ... 53

TABELA 4: Transferência anual de nutrientes pela serapilheira, $(\mathrm{Kg} / \mathrm{ha} / \mathrm{ano})$ e participação em percentagem das frações nos totais dos elementos.

TABLE 4: Annual transfer of nutrients in litter ( $\mathrm{kg} / \mathrm{ha}$ / year) and the participation as a percentage of the total fractions of the elements.

\begin{tabular}{lccccccccc|c|c|c}
\hline & $\mathrm{N}$ & $\%$ & $\mathrm{P}$ & $\%$ & $\mathrm{~K}$ & $\%$ & $\mathrm{Ca}$ & $\%$ & $\mathrm{Mg}$ & $\%$ \\
\hline Folha & 148,51 & 71,86 & 7,56 & 67,50 & 27,24 & 72,16 & 200,66 & 74,55 & 22,04 & 73,86 \\
Galhos & 28,42 & 13,75 & 1,57 & 14,02 & 5,68 & 15,05 & 43,89 & 16,31 & 4,18 & 14,01 \\
F.F.S & 5,57 & 2,69 & 0,44 & 3,93 & 1,54 & 4,08 & 3,13 & 1,16 & 0,69 & 2,31 \\
& & & & & & & & & & \\
Detritos & 24,18 & 11,70 & 1,63 & 14,55 & 3,29 & 8,71 & 21,47 & 7,98 & 2,93 & 9,82 \\
& & & & & & & & & & \\
Total & 206,68 & 100,00 & 11,20 & 100,00 & 37,75 & 100,00 & 269,15 & 100,00 & 29,74 & 100,00
\end{tabular}

$* \mathrm{FFS}=$ flores, frutos e sementes.

conforme o elemento analisado. A contribuição dos detritos em cálcio é de aproximadamente $8 \%$, ao passo que em fósforo é de $14,6 \%$. A fração flores, frutos e sementes, devido a sua pequena massa, tem uma contribuição modesta na ciclagem de nutrientes, no ecossistema estudado.

A Figura 6 exibe o padrão de deposição dos nutrientes estudados, ao longo do ano.

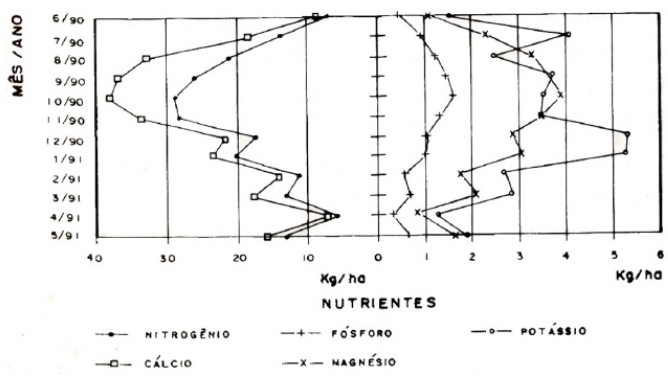

FIGURA 6: Quantidade de nutrientes $(\mathrm{Kg} / \mathrm{ha})$ fornecido durante o ano pela deposição da serapilheira.

FIGURE 6: Amount of nutrients ( $\mathrm{kg} / \mathrm{ha}$ ) provided during the deposition of litter.

Excluindo-se o potássio, os nutrientes demostraram um 
padrão de deposição semelhante ao padrão da serapilheira total. As maiores quantidades anuais de nutrientes foram depositadas na primavera, quando as precipitações foram abundantes e a temperatura média mensal estava em elevação. $\mathrm{O}$ potássio em função da sua suscetibilidade à lavagem, já mencionada, apresentou maior transferência, via serapilheira, em janeiro e fevereiro, no período de menor pluviosidade.

\section{Decomposição da serapilheira}

Durante os levantamentos de dados, observou-se que a manta se distribui desuniformemente sobre o solo na floresta estudada. A Figura 7 permite visualizar a média das quantidades de manta existente sobre o solo em cada mês, evidenciando graficamente o desvio padrão, o que demostra a grande variação entre os locais de coleta. A variabilidade espacial no acúmulo de manta, no sítio de estudo, foi atribuída à distribuição aleatória das espécies, o que implica variação da queda de serapilheira (Tabela 2). A inclinação e pedregosidade da área de estudo também contribui para que a manta se deposite preferencialmente em determinados locais. Através do efeito da gravidade, ocorre redistribuição da serapilheira, que tende a cumular em depressões microtopográficas, como as ocasionadas por troncos caídos, rochas superficiais, etc.

A variação espacial e mensal na quantidade de manta por unidade de área, não permitem detectar qualquer tendência sazonal em seu acúmulo. A quantidade média de manta sobro o solo, calculada para os 12 meses de estudo é de 6,7 ton/ha, com um desvio padrão de $\pm 1,64$ ton/ha. 


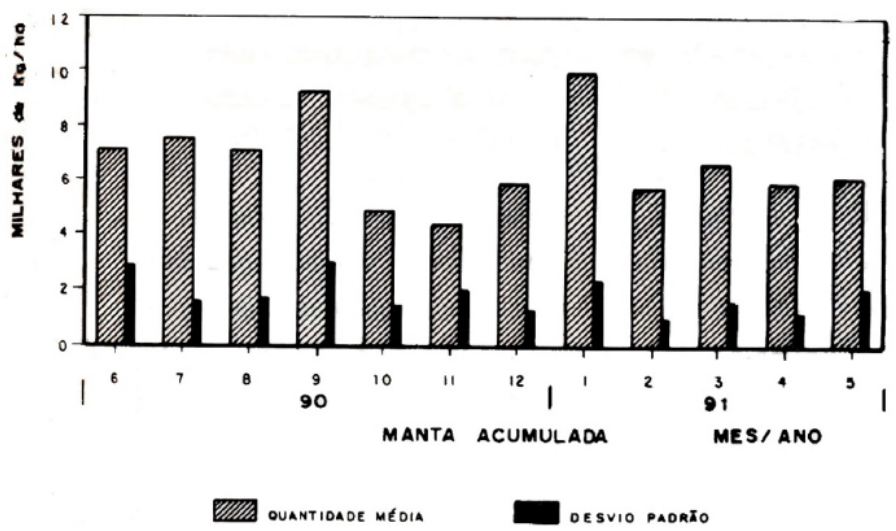

FIGURA 7: Quantidades médias de manta sobre o solo (ton/ha). (Barras estreitas representam os valores de desvio padrão das médias).

FIGURE 7: Average amounts of blanket on the ground (ton / ha). (Narrow bars represent the standard deviation values of the means)

Para comparação com os resultados obtidos neste trabalho, a Tabela 5 demostra, para vários ecossistemas florestais, a quantidade de serapilheira produzida, a massa de manta acumulada, os valores da taxa instantânea de decomposição $(\mathrm{K})$ e o tempo em anos, necessários para a decomposição de $50 \%$ a $95 \%$ da serapilheira, segundo Olson (1963). Segundo o critério adotado por este autor, as florestas com coeficiente K superior a 1 possuem serapilheira de rápida decomposição.

A taxa instantânea de decomposição (K), encontrada na floresta em estudo, $(1,16)$ interpola-se entre os valores estimados por Andrae \& Krapfenbauer (1983) para um povoamento de Araucárias com 17 anos, em Passo Fundo - RS, e os calculados para uma floresta semidecídua de São Paulo (Tabela 5). Entretanto, a taxa de decomposição calculada para esta floresta, refere-se apenas à fração folhas da serapilheira, a qual apresenta uma transformação mais rápida do que a serapilheira como um todo.

A rápida decomposição de serapilheira na floresta em análise 
TABELA 5: Produção de serapilheira (Kg/ha/ano), quantidade de manta $(\mathrm{Kg} / \mathrm{ha})$, taxa instantânea de decomposição $(\mathrm{K})$, e tempo necessário para decomposição de 50\% $(\mathrm{t} 0,50)$ e $95 \%(\mathrm{t} 0,05)$ de uma determinada porção de serapilheira, em anos.

TABLE 5: Litter production ( $\mathrm{kg} / \mathrm{ha} /$ year) amount of web ( $\mathrm{kg} / \mathrm{ha})$, instantaneous rate of decomposition $(\mathrm{k})$ and time required for the decomposition of $50 \%(\mathrm{t} 0,50)$ and $95 \%(\mathrm{t} 0,05)$ of a certain portion of litter, in years.

\begin{tabular}{|c|c|c|c|c|c|c|}
\hline $\begin{array}{c}\text { Tipo de Floresta } \\
\text { e Local }\end{array}$ & $\begin{array}{l}\text { Serapilheira } \\
\text { Produzida } \\
\mathrm{Kg} / \text { ha.ano }\end{array}$ & $\begin{array}{c}\text { Manta } \\
\text { Acumulada } \\
\mathrm{Kg} / \mathrm{ha}\end{array}$ & $\mathrm{K}$ & t 0,5 & t 0,05 & Referências \\
\hline $\begin{array}{l}\text { Fta. Tropical Úmida } \\
\text { Panamá }\end{array}$ & 11.350 & 6.200 & 1,83 & 0,40 & 1,64 & Goley et al.(1978) \\
\hline Floresta Ciliar Panamá & 11.610 & 14.150 & 0,82 & 0,84 & 3,66 & Goley et al.(1978) \\
\hline $\begin{array}{l}\text { Floresta Baixo Montana } \\
\text { Úmida Panamá }\end{array}$ & 10.480 & 4.820 & 2,17 & 0,30 & 1,38 & Goley et al.(1978) \\
\hline $\begin{array}{l}\text { Floresta Montana Andes } \\
\text { Ocidentais-Venezuela }\end{array}$ & 6.970 & 38.000 & 0,18 & 3,80 & 16,30 & $\begin{array}{l}\text { Fassbender \& } \\
\text { Grimm(1981) }\end{array}$ \\
\hline $\begin{array}{l}\text { Floresta Eucalipto- } \\
\text { Austrália }\end{array}$ & 7.500 & 13.100 & 0,57 & 1,22 & 5,26 & $\begin{array}{c}\text { Feller(1980)apud } \\
\text { Vogt et al.(1986) }\end{array}$ \\
\hline $\begin{array}{l}\text { Floresta de Araucaria } \\
\text { angustifolia (17 anos) } \\
\text { - RS* }\end{array}$ & 6.700 & 6.000 & $1,1-0,7$ & $0,6-0,9$ & $2,7-4,2$ & $\begin{array}{c}\text { Andrae \& } \\
\text { Krapfenbauer(1983) }\end{array}$ \\
\hline $\begin{array}{l}\text { Floresta Estacional } \\
\text { Semidecidual - SP** }\end{array}$ & 8.505 & 3.619 & 2,3 & 0,30 & 1,30 & $\begin{array}{l}\text { Poggiani \& } \\
\text { Monteiro Jr. } \\
\quad(1990)\end{array}$ \\
\hline $\begin{array}{l}\text { Floresta Estacional } \\
\text { Decidual - RS }\end{array}$ & 7.762 & 6.700 & 1,16 & 0,60 & 2,59 & Este estudo \\
\hline
\end{tabular}

*Valores estimados indiretamente pelos autores. **Refere-se apenas à fração de folhas da serapilheira. 
deve-se a vários fatores, entre eles, a qualidade do substrato que, dentro de uma mesma região climática, é o fator determinante da taxa de decomposição (SWIFT et al., 1979).

A rápida transformação da serapilheira, produzida continuamente ao longo do ano, assegura uma continuidade do suprimento anual de nutrientes. Isso é particularmente importante para elementos como o $\mathrm{N}$ e o $\mathrm{P}$, os quais apresentam taxas de mineralização semelhantes às taxas de decomposição da matéria orgânica (JORDAN, 1985).

\section{Eficiência de utilização de nutrientes}

A Tabela 6 revela as produções anuais de serapilheira de folhas, as quantidades de $\mathrm{N}, \mathrm{P}, \mathrm{Ca}$ e $\mathrm{Mg}$ transferidos anualmente por esta fração e as correspondentes eficiências de utilização destes nutrientes em alguns ecossistemas florestais tropicais e subtropicais americanos. Verifica-se que para os elementos empregados para determinação da eficiência, a mesma é baixa para as florestas em estudo. Isto sugere que nesta floresta, a produção primária não é limitada pela disponibilidade de nenhum desses elementos.

A baixa eficiência de utilização de N, P e Ca pelas árvores nesta floresta, pode ser explicada por diversos fatores: os solos da área estudada são pouco intemperizados e derivados de rochas efusivas básicas, o que lhes garante um bom suprimento de $\mathrm{Ca}$, $\mathrm{Mg}$ e K. A floresta é a vegetação que ocorre naturalmente na área, transferindo anualmente quantidades relativamente elevadas de bases e material orgânico ao solo. A interação entre vegetaçãosolo-material de origem, garante a manutenção de um elevado teor de bases trocáveis disponíveis à vegetação, mantidas no solo principalmente devido à alta capacidade de troca de cátions, propiciada pela matéria orgânica. 
TABELA 6: Biomassa de serapilheira de folhas produzida anualmente e fornecimento de $\mathrm{N}, \mathrm{P}, \mathrm{Ca}$ e $\mathrm{Mg}$ por esta fração ( $\mathrm{Kg} / \mathrm{ha} / \mathrm{ano})$ e respectivas eficiências de utilização desses elementos, dada pela relação biomassa/elemento, em algumas florestas tropicais e subtropicais.

TABLE 6: Leaf litter biomass produced annually and the supply of N, P, Ca and $\mathrm{Mg}$ in this fraction ( $\mathrm{kg} / \mathrm{ha} /$ year) and their efficiency of the use of these elements, given by the ratio biomass/element in some tropical and subtropical forests.

\begin{tabular}{|c|c|c|c|c|c|c|c|c|c|c|}
\hline $\begin{array}{c}\text { Tipo de Floresta } \\
\text { e Local }\end{array}$ & $\begin{array}{r}\text { Biomas } \\
\text { Folha }\end{array}$ & \begin{tabular}{l|l} 
ssa & N \\
is
\end{tabular} & $\mathrm{P}$ & $\mathrm{Ca}$ & $\mathrm{Mg}$ & Biom/N & Biom/P & $\begin{array}{c}\mathrm{Biom} / \\
\mathrm{Ca}\end{array}$ & $\begin{array}{c}\text { Biom/ } \\
\mathrm{Mg}\end{array}$ & Referência \\
\hline $\begin{array}{l}\text { Floresta Montana } \\
\text { Andes Venezuela }\end{array}$ & 3.381 & 39,0 & 2,1 & 24,8 & 8,8 & 86,7 & 1.610 & 136 & 384 & $\begin{array}{l}\text { Fassbender \& Grimm } \\
\qquad(1981)\end{array}$ \\
\hline $\begin{array}{c}\text { Floresta Tropical } \\
\text { Úmida Terra Firme } \\
\text { Venezuela }\end{array}$ & 7.570 & 121,1 & 2,1 & 13,0 & 32,0 & 62,5 & 3.605 & 582 & 1.455 & Cuevas \& Medina (1986) \\
\hline $\begin{array}{c}\text { Floresta Tropical } \\
\text { Úmida Terra Firme- } \\
\text { AM }\end{array}$ & 5.600 & 86,3 & 1,7 & 12,4 & 9,8 & 64,9 & 3.294 & 452 & 571 & $\begin{array}{c}\text { Klinge \& Rodrigues } \\
\text { (1968) }\end{array}$ \\
\hline $\begin{array}{c}\text { Floresta Tropical } \\
\text { Úmida Terra Firme- } \\
\text { PA }\end{array}$ & 7.757 & 93,0 & 2,2 & 34,7 & 11,1 & 51,2 & 2.162 & 137 & 428 & Silva(1984) \\
\hline $\begin{array}{c}\text { Floresta } \\
\text { Semidecídua-SP }\end{array}$ & 5.895 & 130,0 & 6,9 & 68,4 & 14,2 & 45,3 & 854 & 86 & 415 & Meguro et al. (1979) \\
\hline $\begin{array}{c}\text { Floresta } \\
\text { Semidecídua-SP }\end{array}$ & 6.740 & 138,0 & 7,2 & 155,9 & 22,4 & 48,8 & 936 & 43 & 300 & Carpanezzi (1980) \\
\hline $\begin{array}{c}\text { Floresta } \\
\text { Semidecídua-SP }\end{array}$ & 8.505 & 167,2 & 8,9 & 236,2 & 25,0 & 50,9 & 956 & 36 & 340 & $\begin{array}{l}\text { Poggiani \& Monteiro Jr. } \\
\qquad(1990)\end{array}$ \\
\hline $\begin{array}{c}\text { Floresta Araucária } \\
\text { Paraná }\end{array}$ & 4.060 & 61,2 & 3,7 & 40,4 & 11,7 & 66,0 & 1,097 & 101 & 347 & Britez(1992) \\
\hline $\begin{array}{c}\text { Floresta Subtropical- } \\
\text { RS }\end{array}$ & 5.096 & 148,5 & 7,6 & 200,7 & 22,0 & 34,3 & 671 & 26 & 232 & Este estudo \\
\hline
\end{tabular}

Ci. Fl., v. 3, n. 1, 1993 
A utilização pouco eficiente do fósforo pela vegetação, apesar do teor de $\mathrm{P}$ disponível no solo, determinado por análise, não ser alto, é intrigante. Entretanto, a "disponibilidade" de P no solo é determinada pela solubilidade do elemento em uma solução extratante e, segundo Chapin (1980), sob condições de campo, as plantas podem diferir amplamente na sua habilidade para absorver P de um mesmo solo. Além disso, grande parte do fósforo existente em solos florestais encontra-se na forma orgânica, apresentando taxas de mineralização dependentes do $\mathrm{pH}$ e do teor de cálcio trocável dos mesmos (HARRISON, 1982).

A utilização pouco eficiente de nitrogênio foi atribuída à abundância de árvores de espécies leguminosas existentes na floresta em estudo.

\section{CONCLUSÕES}

a) As metodologias empregadas para estudar a produção de serapilheira e a ciclagem de nutrientes foi satisfatória. A quantificação apenas da queda de folhas já propicia uma boa estimativa da produção da serapilheira;

b) A continuação deste tipo de estudo, por período de tempo mais extenso, permitiria compreender melhor a dinâmica da floresta estudada;

c) A quantidade anual de queda da serapilheira, no primeiro período de observação, foi de 7,76 ton/ha. As menores produções de serapilheira foram verificadas no outono e as maiores na primavera, quando a temperatura média mensal estava em elevação e as precipitações mensais foram abundantes. 
d) O conteúdo de nutrientes é variável, segundo a fração de serapilheira analisada. Na fração detritos encontramse altas concentrações de N, P e Ca. As folhas detêm as maiores concentrações de $\mathrm{Ca}$ e $\mathrm{Mg}$, enquanto a fração composta por flores, frutos e sementes caracterizam-se pelos altos conteúdos de $\mathrm{PeK}$. Os galhos finos apresentam baixas concentrações para todos os elementos estudados;

e) Para o total de serapilheira observa-se pequena variação nas concentrações de nutrientes, no decorrer do ano. Isto significa que, o fornecimento de nutrientes ao solo está mais nitidamente ligado à quantidade de serapilheira produzida do que à qualidade da mesma, ao longo do ano;

f) $\mathrm{O}$ fornecimento de nutrientes, via serapilheira ocorre fundamentalmente através da fração folhas. Esta fração, embora não apresente as maiores concentrações de alguns elementos (N, P, K), é a que mais contribui para a ciclagem de nutrientes, devido a sua grande produção de massa;

g) A taxa instantânea de decomposição da serapilheira, que indiretamente representa a velocidade com que os nutrientes, ligados a ela, são tornados disponíveis, foi de 1,16 . Este valor é considerado alto, segundo o critério de Olson (1963);

h) A relação biomassa/elemento na fração folha de serapilheira é baixa quando comparada com outras formações florestais. Para o nitrogênio foi de 34,3, para fósforo 671, para cálcio 26 e para magnésio 232. A baixa relação entre a biomassa produzida e a quantidade de nutrientes, caracteriza uma baixa eficiência de utilização de nutrientes, pela vegetação da floresta em estudo. Isto significa que a produção primária não é limitada pela disponibilidade dos elementos estudados. 
Dinâmica nutricional em floresta estacional decidual com ênfase ... 61

\section{AGRADECIMENTOS}

Agradecemos à FAPERGS pelo financiamento concedido. Processo n. 90.1860.0 e a Bolsa de Iniciação Científica concedida ao primeiro autor.

\section{REFERÊNCIAS BIBLIOGRÁFICAS}

ANDRAE, F.H.; KRAPFENBAUER, A. Inventário de um reflorestamento de araucária de 17 anos em Passo Fundo-RS. Parte II: Inventário de nutrientes. In: Pesquisas Austríaco-brasileiras. Ed. Única. Áustria, 1983. p.30-35.

ARCOVA, F.C.S.; CICCO, V. de. Fluxo de nutrientes através da precipitação interna e escoamento pelo tronco em floresta natural secundária no parque estadual da Serra do Mar - Núcleo Cunha SP. Bol. Técn. IF. São Paulo, v.41, n.1, p.37-58, março, 1987.

ATTIWILL, P.M. The loss of elements from decomposing litter. Ecology. v.49, n.1, p.142-45, 1968.

BRITEZ, R.M. et al. Deposição estacional de serapilheira e macronutrientes em uma floresta de Araucária, São Mateus do Sul, PR. In: CONGRESSO NACIONAL SOBRE ESSÊNCIAS NATIVAS, 2, São Paulo, 1992. Anais... v.4, p.766-72.

BRAY, J.R.; GORHAM, E. Litter production in forests of the world. Advances in Ecological Research., v. 2, p.101-157, 1964. CARPANEZZI, A.A. Deposição do material orgânico e nutrientes em uma floresta natural e em uma plantação de eucalipto no interior do Estado de são Paulo. Piracicaba, ESALQ/USP, 1980. 107p. Diss. Mestrado. 1980.

CHAPIN, P.S.III. The mineral nutrition of wild plants. Ann. Rev. Ecol. Syst., v.11, p.233-60, 1980. 
COLE, D.W.; RAPP, M. Elemental cycling in florested ecosystems. In: Reichle, D.E., Editor Dynamic properties of forest ecosystems. Cambridge University Press, Cambridge, England, p.341-409, 1980.

CUEVAS, E.; MEDINA, E. Nutrient dynamics whit inamazonian forest ecosistems. In: nutrient flux in fine litter fall and efficiency, of nutrient utilization. Decologia. v.68, p.446-472, 1986.

FASSBENDER, H.W.; Y, GRIMM, U. Ciclos bioquímicos em um ecosistema forestal de los Andes Occidentales de Venezuela. II Producción y descomposición de losresiduosvegetales. Turrialba, v.31, n.1, p.39-47, 1981.

GOLLEY, F.B. et al. Ciclagem de minerais em um ecossistema de Floresta Tropical Úmida. São Paulo: EPU/Editora da Universidade de São Paulo, 1978. 256p.

HARRISON, A.F. Labile organic phosphorus mineralization in relationship to soil properties. Soil Biol. Biochem, v.14, p.343-51, 1982.

HERRERA, R. et al. How human activities disturb the nutrient cycles of a tropical rain forest Amazonia. Ambi., v.10, n.2-3, p.109-14, 1981.

JORDAN, C.F. Nutrient cycling in tropical forest ecosystems. Principles and their application in management and conservation. John Wiley \& Sons, New York, 1985.

KLEIN, R.M. Aspectos fitofisionômicos da Floresta Estacional Decidual na Fralda da Serra Geral (RS). In: CONGRESSO NACIONAL DE BOTÂNICA, XXXV, 1983.Anais... p.73-113. KLINGE, H.; RODRIGUES, W.A. Litter production in anarea of Amazonian terra-firme forest. Part I. Litter fall, organic Carbon and total Nitrogen contents. Amazonian, v.1, n.4, p.287-302. 1968a. KLINGE, H.; RODRIGUES, Litter production in an area of Amazonian terra-firme forest. Part II. Mineral nutrient content of the litter. Amazonian, v.1, n.4, p.303-310. 1968b. 
LEMOS, R.C. Levantamento dos solos do Rio Grande do Sul. Boletim técnico número 30. Ministério da Agricultura, Departamento Nacional de pesquisas Agropecuárias. Divisão pedagógica, Recife, 1973. 431p.

LUISÃO, F.J.; SCHUBART, H.O.R. Litter production and decomposition in a terra-firme forest of central Amazonia. Experentia, v.43, n.3, p.259-64, 1987.

MACHADO, P.F. dos S.; LONGHI, S.J. Aspectos florísticos e fitossociológicos do Morro do Elefante, Santa Maria. Ciência Florestal, v.19, n.3-4, 1993.

MEGURO, M.; VINUEZAM G.N.; DELITTI, W.B.C. Ciclagem de nutrientes minerais na mata mesófila secundária - São Paulo. I Produção e conteúdo mineral de folhedo. Boletim de Botânica da Universidade de São Paulo, São Paulo. v.7, n.7, p.11-31, 1979. MOTA, F.S.; BEIRSDORF, M.I.C.; GARCEZ, J.R.B. Zoneamento agroclimático de Rio Grande do Sul e Santa Catarina. Normais Agroclimáticas, Ministério da Agricultura, Instituto de Pesquisa Agropecuária, v.1, circular n.50, Pelotas, 1971.

OLSON, J.S. Energy storage and the balance of and decomposers in ecological syatems. Ecology, v.44, p.322-31, 1963.

POGGIANI, F.; MONTEIRO Jr.; E.S. Deposição de folhedo e retorno de nutrientes ao solo numa Floresta Estacional Semidecídua em Piracicaba, SP. In: Anais... $6^{\circ}$ Congresso Florestal Brasileiro, Campos do Jordão, São Paulo, 22 a 27 de setembro de 1990, pp.596-602.

PRITCHETT, W.L. Suelos Forestales. Propriedades, conservación y mejoramento. Primeira Ed. México: Limusa, 1986. 634p.

REMEZOV, N.P. Decomposition of forest litter and the cycle of elements in an oak forest. SovietSoil Science, v.7, p.703-11, 1961. SARRUGE, J.R.; HAAG, H.P. Análise química das plantas. Piracicaba, ESALQ, 1974. 56p. 
SARTORI, P.L.; MAGIE FILHO, C.; MANEGOTTO, E. Contribuição ao estudo das rochas vulcânicas da Bacia do Paraná na região de Santa Maria, RS. Revista brasileira de Geociência, v.5, p.141-159, 1975.

SILVA, M.F.F. Produção anual de serapilheira e seu conteúdo mineralógico em Mata Tropical de Terra Firma, Tucuruí-PA. Bol. Museu Paranaense Emilio Goeldi, Botânica, v.1, n.1-2, p.111-58, 1984.

STARK, N. Nutrient cycling. In: nutrient distribution in Amazonian vegetation. Int. J. Trop. Ecol., v.12, p.177-201, 1971.

SWIFT, M.J.; HEAL, O.W.; ANDERSON, J.W. Decomposition in terrestrial ecosystems. Blackwell, Oxford, 1979, 373p.

VITOUSEK, P. Nutrient cycling, and use efficiency. Amer. Nat., v.119, p.553-572, 1982.

VOGT, K.A.; GRIER, C.C.; VOGT, D.J. Production, turnover, and nutrient dynamics of above and belowground detritus of world forest. Advances in ecological research. v.15, p.303-77, 1986. 